\title{
ENTRE O AMOR E O SOFRER - A VIOLÊNCIA CONTRA A MULHER NAS RELAÇÕES AFETIVAS DO SÉCULO XXI: UMA ANÁLISE À LUZ DA SOCIOLOGIA JURÍDICA E DA PSICANÁLISE
}

\author{
Allyne Marie Molina Moreira* \\ Danilo Fontenele Sampaio Cunha ${ }^{* *}$
}

\section{RESUMO}

O presente artigo se constitui em uma pesquisa bibliográfica, onde buscar-se-á compreender a violência contra a mulher no Brasil, sopesar como o Estado Democrático de Direito tem atuado ou poderia desenvolver mecanismos a fim de minimizar esta realidade e, por último, meditar criticamente acerca das possíveis falhas das leis brasileiras que tratam sobre o assunto, em especial a Lei n. ${ }^{\circ}$ 11.340/2006 - Lei Maria da Penha. Apesar de encontrar guarida no ordenamento jurídico brasileiro, observa-se que este ainda é um assunto velado, demandando reflexões pormenorizadas. Neste sentido, vêm-se analisar o tema a partir do olhar da Sociologia Jurídica e da Psicanálise observando a legislação vigente no Brasil. Assim, conclui-se ao final que apesar da violência ter intrinsicamente um caráter antissocial e primitivo, é também um denominador cultural. Diante deste cenário, o Estado precisa ter um olhar diferenciado para essa questão, trabalhando para que a aplicação da lei e a proteção às vítimas seja algo realmente eficaz.

PALAVRAS-CHAVE: Mulher; Violência; Estado Democrático de Direito; Sociologia Jurídica; Psicanálise.

\section{BETWEEN LOVE AND SUFFERING - VIOLENCE AGAINST WOMEN IN THE AFFECTIVE RELATIONS OF XXI CENTURY: AN ANALYSIS PURSUANT THE LEGAL SOCIOLOGY AND PSYCHOANALYSIS}

\begin{abstract}
This article is a bibliographical research, where it will be sought to understand violence against women in Brazil, to consider how the Democratic State of Law has acted or could develop mechanisms in order to minimize this reality and, finally, to meditate critically about the possible flaws of the Brazilian laws that deal with the subject, especially Law no. 11.340 / 2006 - Maria da Penha Law. Although it finds shelter in the Brazilian legal system, it is observed that this is still a veiled subject, demanding detailed reflections. In this sense, we have analyzed the theme from the perspective of Juridical Sociology and Psychoanalysis observing the legislation in force in Brazil. Thus, it is concluded at the end that although violence intrinsically has an antisocial and primitive character, it is also a cultural denominator. Faced with this scenario, the state needs to look at this issue differently, working to make law enforcement and victim protection effective.
\end{abstract}

\footnotetext{
* Mestranda em Direito Privado no Centro Universitário 7 de Setembro - UNI7; Graduanda em Psicologia na Universidade de Fortaleza - UNIFOR; allynemariemm@live.com

** Professor do Curso de Mestrado em Direito Privado no Centro Universitário 7 de Setembro - UNI7; Doutor em Filosofia do Direito pela Pontifícia Universidade Católica de São Paulo - PUC/SP; Juiz Federal; Tem experiência na área de Direito, com ênfase em direito penal e ética profissional; daniloffc@ uol.com.br
} 
KEYWORDS: Women; Violence; Democratic State of Law; Legal sociology; Psychoanalysis.

\section{INTRODUÇÃO}

"Em briga de marido e mulher, ninguém mete a colher."

De acordo com estudos realizados por Freitas e Silva (2014), historicamente a mulher tem passado por inúmeros dificuldades no reconhecimento de seus direitos e garantias fundamentais. Observar o caminho percorrido pelo sexo feminino desde o início dos estudos sociais traz a certeza de que não foi fácil chegar as vitórias que se tem hoje, mas também se percebe que muito ainda é almejado. A luta continua dia a dia, porém nem sempre os resultados são alcançados tão prontamente. Hoje a mulher encontra-se em uma ascensão profissional que a propicia sua independência pessoal, bem como autonomia dentro das relações afetivas. Mas isso ainda não é suficiente para trazer a igualdade entre os sexos, fazendo com que, talvez, essa seja a maior batalha hoje a ser vencida.

Diante desta realidade, pretende-se, a partir de um olhar psicossocial, compreender a questão da violência contra a mulher dentro de suas relações afetivas com homens que ocupem a condição de maridos, noivos, namorados ou mesmo aqueles que estabeleçam com elas algum tipo de intimidade e cumplicidade. Desta forma, buscar-se-á explorar o tema, observando e discutindo quando esses enlaces saem da esfera do socialmente aceitável para um lugar de sofrimento e adoecimento. Falar de relacionamentos patológicos é buscar entender algo que atravessa a compreensão racional e chega, na maioria das vezes, em um lugar de olhares turvos e pouco iluminados.

Tem-se observado que notícias a respeito de violência contra a mulher têm se tornado comum no século XXI. Corriqueiramente, algumas mulheres sofrem dentro de suas relações que, no início, pareciam ser uma história de amor e prosperidade. Homens que têm um lugar de destaque emocional na vida dessas vítimas passam a causar dores sobretudo na alma, levando-as a viver paradoxalmente entre o amor e o sofrimento. São questões que vão das brigas no interior dos lares, onde o Estado tem difícil acesso, à exposições sociais da vítima, podendo chegar ao homicídio.

Cada forma de violência traz consigo suas particularidades, mas todas causam intenso sofrimento, principalmente emocional. Viver esta realidade não é fácil e sair dela, menos ainda. Segundo Dias (2008), os motivos que levam as vítimas a permanecer nesta infelicidade 
são diversos, sendo os mais comuns o medo de denunciar o agressor ou mesmo a dependência econômica. São pessoas que se perderam em seus caminhos para seguir na estrada do outro. Mulheres que cultivam um sentimento sincero, levando-as a crer que, apesar de tudo, aquele é o homem certo para elas.

Perdoada ou esquecida, a violência fica guardada em um canto adormecido de um sujeito latente. Acreditar que o agressor não vai mais cometer o ato, é acreditar que ele afastou-se de sua essência, o que não é fácil. Conforme preleciona Câmara (2010), mudanças ou readaptações do "Eu" podem e devem acontecer, isso mostra que este individuo está em um constante movimento que o leva ao amadurecimento e a progressão pessoal. Mas enquanto isso não ocorre, mulheres passam por situações de indignidade, acreditando que dias melhores virão, enquanto os mais próximos assistem uma história de fatos velados ou contados de forma distorcida.

De acordo com vídeo de campanha publicada no site do G1 (2015), cair da escada, escorregar no banheiro ou tropeçar no tapete são desculpas inventadas e frequentemente contadas com o fim de mascarar a realidade vergonhosa e munida de violência ainda vivenciada por muitas mulheres. A falta de entendimento acerca desta dor em silêncio quando, neste lugar, se poderia ter o apoio Estatal e jurídico, acaba por intrigar profissionais de diversas áreas que lidam diariamente com esta questão.

Diante do exposto, pretende-se, neste trabalho, responder as causas e motivações psicossociais que ainda levam tantas mulheres a viver, em silêncio, uma relação que segue para o caminho da violência, sopesar como o Estado Democrático de Direito tem atuado ou poderia desenvolver mecanismos a fim de minimizar esta realidade e, por último, meditar criticamente acerca das possíveis falhas das leis brasileiras que tratam sobre o assunto, em especial a Lei n. ${ }^{\text {1 }}$ 11.340/2006 - Lei Maria da Penha.

Unindo-se aos presentes estudos e primando por uma análise interdisciplinar, buscarse-á, além dos argumentos próprios do campo da Sociologia Jurídica, trazer, à discussão, ponderações do Direito e da Psicologia, áreas estas em que os articulistas tem afinidade e procura ampliar seus conhecimentos, justificando-se, assim, a escolha deste tema.

Como forma de observação, empregar-se-á o método bibliográfico, buscando abarcar o tema a partir de referências teóricas. (QUEIROZ, 2015) Para isso, elegeu-se o modelo descritivo-analítico, procurando realizar leituras interpretativa do material colhido e compreendê-lo em sua propriedade. (BEUREN, 2004)

Revista de Movimentos Sociais e Conflitos | e-ISSN: 2525-9830 | Salvador | v. 4 | n. 1 | p. 111 - 131 | 


\section{A VIOLÊNCIA CONTRA A MULHER E SEUS ASPECTOS PSICOSSOCIAIS}

Maria, Maria, é o som, é a cor, é o suor

É a dose mais forte e lenta

De uma gente que ri quando deve chorar

E não vive, apenas aguenta

(Milton Nascimento e Fernando Brant)

Acredita-se que nenhum pesquisador saberia dizer, com precisão, quantas Marias tiveram que passar pela dor da violência, seja ela física, psíquica, emocional e/ou social, para que esse assunto começasse a ter relevância nas discussões científicas. Quantas delas precisaram se esconder para não passar por constrangimentos, nem serem julgadas ou mal interpretadas. Quantas vítimas, antes da discussão social surgir, sentiram seus corpos agredidos e seus corações dilacerados. O caminho foi longo e sabe-se que ainda há muito a ser percorrido, conquistado e debatido. Para muitas dessas vítimas, a música "A Estrada", do grupo Cidade Negra (1998), expressa uma grande verdade quando, em sua melodia, diz: "Você não sabe o quanto eu caminhei/Pra chegar até aqui/Percorri milhas e milhas antes de dormir/Eu não cochilei/Os mais belos montes escalei/Nas noites escuras de frio chorei”.

No Brasil, esta discussão tem se expandido e tomado um lugar de destaque dentro dos estudos de vários campos científicos. Profissionais têm se debruçado sobre esta temática, trazendo esperanças às vítimas que ainda hoje se mantem, muitas vezes, caladas sob a vergonha e a discriminação. Pesquisadores conversam acerca do assunto, o qual tem a cada dia adotando uma nova roupagem. O Legislativo, essencial para a ordem social, não se furtou desta empreitada, criando mecanismos legais e atualizando outros que, juntos, favorecessem o combate a violência contra a mulher em suas mais variadas esferas. Como exemplo tem-se a Lei n. ${ }^{\text {o } 11.340 / 2006 ~-~ L e i ~ M a r i a ~ d a ~ P e n h a, ~ c r i a d a ~ c o m ~ o ~ i n t u i t o ~ d e ~ e r r a d i c a r ~ e s t e ~ t i p o ~}$ especifico de crime. Faz mister que o Estado intervenha em defesa dessas vítimas. Políticas públicas precisam ser efetivadas e leis, cumpridas. O caminho da luta contra este drama ainda é longo, mas precisa ser seguido. De acordo com Dias (2008, p. 21):

Até o advento da Lei Maria da Penha, a violência doméstica não mereceu a devida atenção, nem na sociedade, nem no legislativo e muito menos no Judiciário. Como eram situações que ocorriam no interior do 'lar doce lar', ninguém interferia. Afinal, 'em briga de marido e mulher ninguém põe a colher'!

A criação de juízos especiais para o julgamento de delitos menores foi determinada pela Constituição Federal. A Lei dos Juizados Especiais veio dar efetividade ao comendo constitucional e significou verdadeira revolução no sistema penal brasileiro. A criação de medidas despenalizadoras, a adoção de um rito sumaríssimo, a possibilidade de aplicação da pena mesmo antes do oferecimento da acusação e mesmo sem discussão da culpabilidade, agilizaram o julgamento dos crimes considerados de pequeno potencial ofensivo. Com isso a Justiça desafogou-se,

Revista de Movimentos Sociais e Conflitos | e-ISSN: 2525-9830 | Salvador | v. 4 | n. 1 | p. 111 - 131 | 
ganhou celeridade e diminui a ocorrência de prescrição, emprestando maior credibilidade ao Poder Judiciário.

Infelizmente, muitos casos de violência doméstica não são registrados junto às autoridades, dificultando a ajuda eficaz do Estado e o real controle estatístico. Grande parte das vítimas acreditam que a vida é assim mesmo, que o relacionamento está apenas atravessando uma fase ruim que logo vai passar, e outras são dependentes econômica e/ou psicologicamente dos parceiros, preferindo não seguir com esse assunto adiante. Para aqueles que têm contato próximo com essa realidade, não é difícil deparar-se com tantas pretextos e explicações que não justificam tamanha atrocidade, levando-os a crer que essa problemática não pode ser deixada de lado. De acordo com Hermann (2008, p. 16):

Há um lugar, entretanto, em que Marias e Marias debatem-se entre amor e ódio, entre carícias e o bofetão, entre a doçura da intimidade e o gravame da ofensa: dentro de casa. Este é, sem dúvida, o lugar - físico e simbólico - onde a angústia de centenas de Marias é retrato da mais insana das dores: a dor do amor que vira ódio para depois tornar a ser amor; a dor da confiança que se transforma em decepção e em seguida cede espaço à esperança. Algumas dessas Marias atravessam infância, juventude, maturidade e velhice vivendo e revivendo o ciclo perverso que lhe rouba alegria e serenidade. Ensinam, por condutas e palavras, filhos e filhas que a vida é assim mesmo. Sem querer, sem pensar, institivamente, perpetuam no descendentes o padrão cruel e insano de sua própria dor. Outras - menos afortunadas - encontram a morte precoce, a invalidez e a doença. Outras ainda rompem grilhões e recomeçam, na maioria das vezes num exercício heróico de bravura, que lhes custa outro tanto de dor. (grifo do autor)

Conforme o exposto, a Lei Maria da Penha foi agente de transformação, facilitando a justiça e evitando a impunidade. Apesar da violência contra a mulher ser um crime, é geralmente, encoberto pelas fechaduras das portas, cortinas das janelas e bocas caladas, apesar de socialmente reprovável e constitucionalmente indigno, ferindo direitos e garantias fundamentais. Não há como fechar os olhos para esse fato, nem tolerar a falta de cuidado estatal correspondente. Assim, olhares interdisciplinares precisam estar constantemente voltados para esta realidade, observando e agindo na medida de sua necessidade. Para isso, áreas como a Psicanálise e a Sociologia são indispensáveis para ajudar a suprir tamanha demanda, colaborando de forma significativa para o presente estudo.

\subsection{A violência contra a mulher como resultado de uma relação patológica}

"Todo homem carrega seus demônios em sua alma e o que faz uns permanecerem nas palavras e outros recorrerem ao ato ainda constitui um enigma. (...) O insuportável da alternativa que se coloca no plano imaginário 'ou ele ou eu' revela que é só a partir de um simbólico que poderia haver um espaço para caberem dois. ”

(Zilda Fabris) 
Analisar a violência contra a mulher não é uma tarefa fácil. Os motivos que levam a prática deste tipo de ato, bem como aqueles que fazem com que as vítimas aceitem e perseverem nestes relacionamentos adoecidos, requer estudos mais aprofundados. Neste sentido, a psicanálise, bem como outros ramos da psicologia, e a psiquiatria, buscam apresentar explicações para estes fatos. A agressividade é considerada como uma característica própria da espécie humana. No entanto, quando demonstrada de forma frequente e/ou severa, pode ser manifestação de uma anormalidade psíquica, na qual o sujeito não é capaz de vivenciar os fatos dentro daquilo que se reconhece como socialmente aceitável, passando a ter características próprias de um comportamento patológico, construído a partir das experiências vividas desde a infância precoce. Ao tratar acerca da origem e manutenção do comportamento agressivo na infância e adolescência, Barros e Silva (2006, online) prescrevem que:

O desenvolvimento de condutas agressivas ao longo da infância e adolescência tem sido alvo de inúmeros estudos que pretendem responder, basicamente, questões referentes à origem e à manutenção da agressividade durante o percurso da vida. O comportamento agressivo é próprio da espécie humana e apresenta múltiplas configurações. Ele pode ser expresso pela via motora, através de movimentos de ataque ou fuga; pela via emocional, com a experimentação de sentimentos de raiva e ódio; pela via somática, como a apresentação de taquicardia, rosto ruborizado, além das demais reações autonômicas; pela via cognitiva, através de crenças de conquistas sem que importem os meios, planos de ação que envolvem a manipulação do meio; e finalmente, a via verbal, da qual o indivíduo vai utilizar-se do sentido das palavras para expressar controle em relação aos outros (Fariz, Mias \& Moura, 2005).

Esta abordagem da agressão refere-se à agressão instrumental, ou seja, aquela que apresenta uma função dentro do ambiente em que está sendo utilizada. Isso significa que o indivíduo tenta obter o controle de seu meio através de comportamentos agressivos, tais como gritar, ameaçar, quebrar ou xingar (Fariz et al., 2005).

A partir desta definição, pode-se observar que, ao longo do processo de maturação, crianças e adolescentes exibem comportamentos agressivos. Entretanto, se essas condutas se mostram severas e freqüentes, elas podem indicar sinais de psicopatologia (Kendall, 1991).

As fases mal vivenciadas na primeira infância podem justificar diversas ações e reações futuramente expressadas por cada um de nós. Para os estudos psicanalíticos, a subjetividade se desenvolve desde que o bebê está no ventre de sua mãe, ou até mesmo quando este ainda pertence apenas ao campo do desejo e do imaginário, o que se denomina "banho de linguagem". Desejar ou não um filho e ajuda-lo a passar por todas os momentos da maneira mais adequada é uma tarefa importante e complexa. É na interação com os outros que cada um se constitui, edificando o seu inconsciente e estabelecendo relações próprias do 
campo do simbólico, com tudo aquilo que se tem contato, de acordo com cada etapa da vida.

Santos e Ghazzi (2012, online) ressaltam que:

Se falamos em transmissão através do inconsciente e entendemos o inconsciente como função simbólica determinada por significantes, vejamos agora de que modo o inconsciente se forma para a criança e de onde partirá toda a cadeia significante, responsável pela transmissão psíquica. Esse caminho irá rumo ao problema colocado, a saber, qual a importância da transmissão psíquica na constituição do sujeito. Veremos que a transmissão psíquica é necessária e concomitante com a constituição do sujeito. Sabemos que toda criança já está sendo constituída psiquicamente mesmo antes de seu nascimento através de um banho de linguagem. Esse banho existe no seio de sua família, e se dá pelo encontro de duas linhagens. Cada uma terá sua história com os ditos e os não ditos, que fazem sua especificidade (Szejer, 1997). Nesse banho de linguagem, estarão diversos significantes que serão transmitidos pelos pais e pelas pessoas que estão ao redor da criança, sempre considerando a cultura em que a família está inserida. Nessa perspectiva, a formação do sujeito ocorre através da relação com o outro e o Outro (linguagem).

Assim, cabe aos pais, ou aqueles que desempenham tal função, mediar os momentos vivenciados na infância, participando e permitindo o amadurecimento. $\mathrm{O}$ contato com a realidade nem sempre é fácil, mas sim necessário. As experiências da fase pueril determinarão muito da constituição psíquica de cada indivíduo e do comportamento que será adotado por estes na fase adulta. É na intersubjetividade que o sujeito se constitui e isso se dá desde as primeiras etapas da vida. A psicanálise busca compreender com mais propriedade a origem destas condutas sociais para, assim, encontrar soluções para cada caso concreto. Pode-se dizer que os estudos psicanalíticos servem como base para a compreensão do sistema social, analisando as pessoas em suas mais profundas e complexas estruturas psíquicas. Conforme Lamanno-Adamo (1999, online):

A psicanálise tem mostrado como a apropriação pelo sujeito de seu corpo, de sua identidade sexual e de sua mente, constrói-se a partir de uma intersubjetividade. Winnicott (1985) e Bion (1962) enfatizaram o papel vital de mediação que os pais desempenham para tornar produtivo na criança o desenvolvimento da imagem corporal, do senso de identidade e do pensamento simbólico. Um ambiente que não se ajusta adequadamente à urgente sensação de um recém-nato pertencer a uma dinâmica familiar, que não propicia discriminar fatos de fantasias, contribui para o desenvolvimento de indivíduos que sofrem de constantes ameaças de desintegração do ego. Desenvolve-se então um sistema de defesas altamente organizado e vigorosamente mantido, onde predominam a repressão, a negação e a recusa, com o objetivo de proteger o ego da ansiedade excessiva produzida pelo contato com uma experiência que não pode ser assimilada. Para proteger o ego da ansiedade excessiva, o indivíduo distorce seu contato com a realidade, obstruindo o acesso à consciência e eliminando os conteúdos mentais afetivos e ideativos. Está assim estruturado um campo fértil para a proliferação da violência. Entendo aqui violência, como a expressão física tanto do amor como do ódio, desvinculados do interesse pela vida e pela verdade (Bion, 1992a) e, portanto, apresentando-se em estado selvagem e apavorante.

Revista de Movimentos Sociais e Conflitos | e-ISSN: 2525-9830 | Salvador | v. 4 | n. 1 | p. 111 - 131 | 
Ao refletir sobre a agressividade destrutiva, Motta (1989) escreve acerca dos aspectos criminais do estupro e, em comparação, afirma que este, assim, como outros tipos de violência, se dá a partir de um sentimento de inferioridade do criminoso e uma necessidade de subjugar a vítima. Para o autor, o comportamento agressivo é, sobretudo, um desejo de se auto afirmar, demonstrando poder e superioridade. Pode ser fruto de uma desestrutura emocional no momento de expressar suas vontades, optando pelo caminho mais fácil: o de diminuir o outro para, assim, se mostrar um ser mais elevado e dominador. Este entendimento não afasta a ideia de ser a agressividade um resultado do período pueril, mas confirma a premissa de que as experiências negativas vividas nessa fase podem acarretar uma baixa autoestima suficiente a gerar esta necessidade socialmente deplorável de se manifestar no mundo. Muitas vezes esse também é o motivo base para a violência doméstica. Conforme o citado pesquisador:

Estudos modernos da sexualidade e dos aspectos criminais do estupro tendem a demonstrar que a agressividade usada pelo estuprador visa mais a uma intensão de subjugar a vítima do que, propriamente, à satisfação sexual (Volk, 1985). Parece mais uma necessidade de poder sobre a vítima do que um impulso sexual incontrolável de um 'tarado'. (...) Infelizmente, ainda se prefere o poder e se pretere o amor, em muitas situações. (...) É, no fundo, uma interação violenta muito semelhante à do estupro. (MOTTA, 1989, p. 57)

Neste sentido, entende-se que o comportamento agressivo de quem pratica a violência contra a mulher pode ser algo próprio do campo da patologia e do mal desenvolvimento da subjetividade. No entanto, a sociedade não pode aceitar tal realidade, nem acatar esta explicação como suficiente. Concorda-se com a premissa de que os seres adoecidos precisam ser respeitados e tratados. Assim como também defende-se que cabe ao Estado promover a saúde, inclusive a psicológica, de todos os seus cidadãos, implantando políticas públicas a fim de acolher e responder a tal demanda. Mas, por outro lado, as mulheres vítimas desta realidade sofrem um resultado que não foi provocado por elas e isso não pode ser esquecido.

Diante do exposto, acredita-se que mesmo abrigando os aspectos patológicos do agressor, este precisa ser punido. A violência doméstica é crime e o comportamento de seus autores não pode ser ignorado. Ter um olhar humanizado sobre essas pessoas faz parte de um entendimento constitucional, mas isso não significa acatar qualquer atitude que favoreça à impunidade.

Por outro lado, a dor da vítima não pode ser deixada de lado. Ao mesmo passo que a violência pode ser causada a partir de uma subjetividade mal elaborada do agressor, é preciso observar quais consequências psicológicas poderão atingir as vítimas e quais os motivos que

Revista de Movimentos Sociais e Conflitos | e-ISSN: 2525-9830 | Salvador | v. 4 | n. 1 | p. 111 - 131 | 
as levam a permanecer em um relacionamento de dor. Entende-se que pode haver ali, naquela ralação doentia, um lugar de gozo, na qual aquelas mulheres não conseguem desvincular-se. $\mathrm{O}$ "Eu" de cada sujeito se constitui a partir dos contatos obtido na infância e, assim como o agressor, as vítimas são aquilo que elas aprenderam a ser. Sobre o assunto, Câmara (2010, online) aponta que:

Talvez por colocarem o Eu como o centro do aparelho psíquico e supervalorizarem o que ele tem de consciente, alguns seguidores o confundiram com o próprio sujeito, que se posiciona de determinada forma diante do mundo, que se desenvolve com a experiência e a educação. Para estes, então, trata-se de adaptá-lo melhor às exigências da sociedade moderna. Mas o Eu é o lugar dos conflitos, seus mecanismos de defesa são inconscientes, e estes conflitos inconscientes geram efeitos poderosos na vida mental, muitas vezes sem nunca se tornarem conscientes — isso pelo fato de o Eu manter uma força constante de repressão.

De fato, ele não é originário, é desenvolvido, erigido a partir do Isso. Em "Sobre o Narcisismo" (FREUD, 1996), ele afirma que o Eu é desenvolvido pela formação do narcisismo primário, que une as pulsões parciais. Antes, no estádio do autoerotismo, estas pulsões parciais estavam anarquicamente distribuídas, ligadas à excitação de uma zona erógena; agora elas convergem para o investimento libidinal do Eu. Doravante, o Eu torna-se objeto de amor para os impulsos do Isso. O narcisismo secundário é a libido objetal que retorna para o Eu. Ele é um precipitado de identificações objetais abandonadas pelo Isso.

Este Eu ideal do narcisismo primário, que é investido pela libido, é substituído pelo ideal do Eu no momento do declínio do complexo de Édipo. O Supereu torna-se a instância crítica, vigilante. Muitas vezes, utiliza sua força de forma desmedida, exerce seu poder tiranicamente, ameaçando a unidade do Eu com sua pulsão de morte não fusionada.

Freud fala de um amadurecimento do Eu, o qual, ao longo do tempo, se tornaria mais forte e, consequentemente, exerceria sua função de intermediação de forma mais harmoniosa, tornaria uma boa parte do Isso consciente, não se submeteria tanto ao imperativo categórico do Supereu e manteria uma relação mais salutar com o mundo externo. (grifo do autor)

Submeter-se a homens violentos e permanecer nesta relação faz parte de uma característica psíquica distorcida, talvez uma consequência de experiências vivida ainda na meninice. Ainda podemos verificar mulheres criadas para casar, ser mãe e constituir família. Nessas hipóteses, separar-se do companheiro significa separar-se de seu próprio "Eu". É no outro que a mulher se determina. Conforme Cavalcante (2001, p. 15 e 16):

O livro da Bíblia que fala do aparecimento do ser humano, o Gênesis, relata que a mulher nasceu da costela do homem. Deus percebeu o homem muito triste e disse que não era bom que ele estivesse só. Mergulhou-o num sono profundo, tirou-lhe uma costela e, dela, fez a mulher, fiel e eterna companheira!

(...)

Essas são questões muito antigas e instigantes para a análise e para o entendimento. Eu preciso do outro para ser. Nele, eu me determino. Sou. Completo-me no outro que me reconhece. Sou por causa do outro.

Para algumas mulheres, relacionar-se com um homem significa encontrar o falo tão desejado na infância, criando uma interdependência em relação aquele ser. Dentre as várias 
fases vividas pela criança, é na castração que esta, percebendo a perda do amor do pai, voltase para a sociedade em busca do "Outro", o qual detém o falo tão almejado. Esta busca pelo falo é intensa e pode mudar de objeto ao longo da vida. No entanto, há relações que saem daquilo que se poderia julgar normal e entram em um campo da patologia, onde essa busca torna-se doentia. Para Souza (2011, online)

Todavia, foi Lacan quem deu um passo à frente, além do Édipo freudiano, enfatizando a relação da menina com a mãe como o cerne da feminilidade - a mãe como a mulher do pai, como objeto de amor que precisou deixar para seguir seu caminho de mulher ao lado de um Outro, portador do falo. Assim, o psiquismo feminino se constitui sob a ameaça da perda do amor. A perda primordial faz esse sujeito lidar com uma falta-a-ser, que lhe é constituinte, algo presente em ambos os sexos. Contudo, a mulher lida com uma outra falta, que é da ordem do corpo, portanto, uma dupla falta. A mãe não consegue nomear a falta que a castração promove na filha, uma fez que ela mesma é um ser castrado. Seu olhar apresenta um furo inquiridor da ausência de palavras. Esta segunda falta diz respeito a um corpo que não possui o suporte simbólico de que necessita para a constituição de seu sexo. Trata-se mesmo de uma ausência, que obriga a mulher a se utilizar do amor como uma suplência, um substituto do falo. Busca o falo no corpo do homem, e faz isso pelas vias do amor e de seus derivados. Assim, o feminino se constitui algo da ordem do inominável, não dito. Por esta razão, a mulher deseja ser amada por um homem que a nomeie enquanto mulher, que lhe conduza ao lugar do "outro" sexo, o feminino.

Desta forma, entende-se que tanto agressor quanto vítima são merecedores de um olhar sensível. Esta realidade vivenciada por tais personagens não é, para a psicanalise, algo que se deve ignorar. São comportamentos não salutares, os quais podem vir a prejudicar a harmonia individual e social das partes. Sair dos relacionamentos insalubres pode ser fácil para umas, mas insuportáveis para outras. Não se pode fechar os olhos para reações deste tipo, devendo trabalha-las para que seus autores possam viver saudavelmente na sociedade, permanecendo ou não nessa relação.

\subsection{Aspectos sociais da violência doméstica: a sociologia jurídica como base teórica do direito}

A violência contra a mulher ainda é uma realidade que atinge milhares de brasileiras e vem machucando famílias inteiras ao longo dos tempos. Estudos apontam para a possibilidade de ser este um problema cultural, resultado de tradições que influenciam diretamente nos costumes e comportamentos. Assim, pode-se observar, por exemplo, músicas, coreografias e produções de televisão que fazem apologias a não valorização da mulher e trazem em destaque a naturalidade de um patriarcalismo rude, onde a macheza do homem diz muito sobre a sua identidade. Para muitos, ser do sexo masculino significa ser forte, ser superior e jamais deixar-se rebaixar. Acreditando-se que os indivíduos são também resultado do meio, 
atribuir as produções culturais uma parcela de culpa no contexto da violência doméstica, não seria algo absurdo. Segundo Brilhante (2015, online):

\begin{abstract}
Uma região não é uma mera delimitação geográfica. Longe disso, trata-se de uma construção de poderes e de identidades. Segundo Bourdieu (1989), a definição de uma identidade, incluindo a regional, passa por objetos de representação mentais percepções, conhecimentos e interesses dos agentes sociais em questão - e objetais ações estratégicas que visam determinar a representação mental que os outros fazem das propriedades e de seus portadores.

(...)

Se o povo é explorado pelo poder estabelecido, é nas figuras que contrariam e resistem a essa força que o povo vai buscar seus ídolos e seus heróis. O xaxado, sendo a dança dos "cabras de lampião", assume qualidade inconteste de ser uma "dança macha" e, portanto, pertinente a um verdadeiro "cabra da peste" nordestino, assim como seu "primo", o baião e, consequentemente, o próprio forró. A grande força da imagem do cangaço no imaginário do nordestino resiste no fato de ele congregar todas as qualidades valorizadas pelo imaginário popular. Força, valentia, rudeza, violência - o cangaceiro era a expressão máxima da masculinidade nordestina. Em 'O Andarilho', de Luiz Gonzaga, o protagonista considera melhor viver no cangaço que ceder aos avanços da civilização.
\end{abstract}

Neste sentido, pesquisas realizadas a respeito da música popular brasileira revelam letras que apontam a violência contra a mulher como algo normal a aceitável. Bryan e Villari (2014) relembram, em sua obra, o samba "Mulher de Malandro", compostas por Heitor dos Prazeres, no ano de 1932, e gravada por Francisco Alves, no mesmo ano. Na música, o compositor traz a ideia de uma mulher que não se importa em apanhar e que, pelo contrário, aumenta o afeto pelo parceiro a medida que é desprezada pelo mesmo. Apresenta uma companheira que aguenta tudo, inclusive a dor física, e, além disso, responde a agressão com carinho e amizade, sentindo-se bem com aquela forma doentia de relacionamento. De acordo com a canção:

Mulher de malandro sabe ser/Carinhosa de verdade/Ela vive com tanto prazer/Quanto mais apanha/A ele tem amizade/Longe dele tem saudade/ Muitas vezes/Ela chora/Mas não despreza o amor que tem/Sempre apanhando e se lastimando/E perto do malandro/Se sente bem (BRYAN; VILLARI, 2014)

No entanto, apesar de perceber o significativo prejuízo social causado pela cultura que, algumas vezes, se apresenta de forma medíocre e sem valores -, não seria suficiente atribuir, apenas a esta, a causa para a dolorosa realidade. Os motivos que levam uma relação a tornar-se violenta perpassa por um entrelaçar de fatores, os quais não são facilmente alcançados. A violência doméstica tem nuances próprias da subjetividade, a qual não se pode atingir sem que se tenha um olhar empático à causa. As marcas, na maioria das vezes, não se limita as manchas arroxeadas, nem as dores físicas, mas são dores cravadas na alma, e acarretam fortes influências negativas na vida individual e coletiva das vítimas, fazendo com 
que a convivência social se torne um teatro difícil de ser interpretado. Para D'Avila Neto (1980, p. 21 e 22):

\begin{abstract}
É bastante difícil conduzir uma discussão teórica sobre o fato feminino, ou sobre a condição feminina, sem cair nas explicações por vezes reducionistas, do freudismo ou do marxismo vulgares. Nada pode ser tão preconceituoso quanto o mascaramento das ideologias dominantes pela cientificidade. Nada é tão insuportável quanto a intolerância se revestir em sabedoria, e a ignorância se transmutar em postulados.

O assunto mulher evoca inúmeras representações: papéis, status, modelos de comportamentos, mitos, expectativas sociais, luta de classe e/ou de sexos, afetos, preconceitos, tabus, interditos morais.
\end{abstract}

Anuindo com a ideia apresentada por Reale (2004), entende-se que o Direito é uma ciência que vem à reboque dos acontecimentos sociais e que as normas nada mais são do que o resultado da junção de fatos e valores. Assim, acredita-se que a Sociologia Jurídica tem uma influência significativa na luta contra os empasses vivenciados em sociedade, dentre eles, a violência contra a mulher. É papel da Sociologia apontar os problemas sociais de cada época, auxiliando o corpo jurídico a reger a sociedade da melhor forma possível. Para isso, o Estado como um todo deve estar atento às mudanças apresentadas e utilizar-se dos mecanismos possíveis para dirimi-las. Segundo Madeira e Engelmann (2013, online)

O uso do conhecimento sociológico por parte dos juristas, com muita frequência, traz implícita uma tentativa de redefinição crítica da teoria e dos diversos ramos disciplinares, visando maior aproximação da aplicação das normas ao contexto histórico e social em que se insere o ordenamento. Ou seja, busca-se, através da sociologia, construir um ramo do conhecimento jurídico com foco principal nos aspectos sociais e políticos que circundam a aplicação de normas, a organização do sistema judicial, a formação dos bacharéis e a estruturação das carreiras jurídicas, aspectos que são considerados, por alguns juristas, como "externos" ou estranhos ao mundo do direito.

Diante do exposto, conclui-se que a sociologia, ao lado de diversas outras áreas não menos importante, desempenha um papel essencial na tentativa de solucionar o problema da violência contra a mulher. É através desta ciência que se observa e analisa, em profundidade, fatos próprios de cada grupo social, compreendendo suas especificidades e reconhecendo suas demandas. No Brasil, país onde a extensão territorial é significativa, não há como generalizar o seu povo, muito menos como aplicar os mesmos "remédios" para solucionar problemas em todas as áreas. (LIMA; YASUI, 2014) Para cada lugar o seu destino e para cada povo a sua percepção.

\title{
3 O ORDENAMENTO JURÍDICO E A MULHER
}

O Ordenamento Jurídico nasce como meio de controle e transformação social. Assim, no mundo das ideias, propõe-se formas de condutas aceitáveis, esperando que a paz e o bem- 
estar sejam assegurados. Para isso, o corpo legal busca atender as demandas já postas na sociedade, como também aquelas que, a partir de um juízo de valor, são consideradas relevantes. Neste sentido, a mulher vem ocupar um lugar de destaque, tanto na Constituição Federal quanto em leis específicas. O amparo ao sexo feminino é legalmente eficaz, facilitando a justiça e buscando promover a igualdade.

\subsection{A violência contra a mulher $x$ a Constituição Federal de 1988}

A força do direito deve superar o direito da força. (Rui Barbosa)

A Constituição Federal de 1988 traz em seu bojo diversas regras, princípios, direitos e garantias fundamentais a fim de proporcionar ao seio social uma vida digna e realizada. No entanto, nem sempre isso acontece na realidade. Na verdade, o que se pode perceber é a desigualdade e o desrespeito humano nas mais variadas esferas, demonstrando uma falha que separa o ideal apresentado na Carta Magna da realidade atual. Cidadãos ainda são desrespeitados diariamente por motivos que deveriam ser considerados imperceptíveis como, por exemplo, a opção sexual, a cor da pele, os defeitos físicos ou, simplesmente pelo fato de ser mulher. O preconceito e a discriminação são elementos presentes até hoje na sociedade, fazendo com que esta esteja ainda muito distante daquilo que foi garantido no texto legal. (BANDEIRA; BATISTA, 2002)

No que diz respeito a violência doméstica contra a mulher, entende-se, primeiramente, que o agressor fere a Constituição naquilo que diz respeito à dignidade da pessoa humana. A liberdade de expressar sua raiva e seu desamor pela companheira e utilizar-se da força para impor sua vontade iria de encontro ao prescrito no artigo $1^{\circ}$, inciso III da Lei Maior, quando o mesmo estabelece que: "art. $1^{\text {o }}$ A República Federativa do Brasil, formada pela união indissolúvel dos Estados e Municípios e do Distrito Federal, constitui-se em Estado Democrático de Direito e tem como fundamentos: III - a dignidade da pessoa humana”. Considerar-se superior ou proprietário da companheira, é submete-la a uma situação indigna, com a qual o Estado não comunga. Neste momento, o Direito Público deve confundir-se com o Privado, adentrando a intimidade dos lares a fim de garantir a aplicação daquilo que foi estabelecido constitucionalmente. Conforme Casique e Furegato (2006, online):

A violência manifesta-se no físico assim como em todas aquelas formas nas quais se oprime, impossibilita ou se violam as garantias individuais das pessoas. Por tal motivo, observa-se que todas as definições, concordam que a violência é qualquer ato exercido contra a dignidade da mulher, independente de suas origens.

Revista de Movimentos Sociais e Conflitos | e-ISSN: 2525-9830 | Salvador | v. 4 | n. 1 | p. 111 - 131 | 
No entanto, a proteção da mulher, bem como da unidade familiar, não se limitou apenas a questão da dignidade humana. Manifestando-se especificamente, a Carta Magna preceitua, em seu artigo 226, o qual foi estabelecido como base legal para a Lei n. ${ }^{\circ}$ 11.340/2006 - Lei Maria da Penha, que "art. 226 A família, base da sociedade, tem especial proteção do Estado". E, não permitindo que as autoridades permaneçam em uma posição inerte, o Poder Legislativo completa o citado artigo afirmando que " $§ 8^{\circ} \mathrm{O}$ Estado assegurará a assistência à família na pessoa de cada um dos que a integram, criando mecanismos para coibir a violência no âmbito de suas relações." Neste sentido, entende-se que o Brasil possui regras que presam pela boa convivência familiar e social, avistando, no seio legal, uma vida digna e saudável para todos.

A partir dos pontos aqui apresentados e diante da forte opressão vivenciada por algumas vítimas deste tipo de relação patológica, a Lei Maria da Penha foi sancionada em 07 de agosto de 2006, buscando devolver as pessoas do sexo feminino o direito de ser sujeito novamente.

\subsection{A Lei Maria da Penha - Uma lei com nome de mulher}

Um dia, quando olhares para trás, verás que os dias mais belos foram aqueles em que lutaste. (Sigmund Freud)

No dia 29 de maio de 1983, uma mulher com o nome de Maria da Penha Maia Fernandes foi vítima de um fato criminoso que mudaria sua vida para sempre. Seu próprio marido, forjando um assalto e com o uso de uma espingarda, a atingiu nas costas, tornando-a paraplégica. No entanto, os comportamentos agressivos praticados por este homem não iniciaram a partir deste episódio, nem findaram com ele. Maria sofreu por muito tempo e, não aceitando tal situação, criou coragem para contar a sua história e lutar para que outras mulheres não tivessem este mesmo destino. O fato, ao contrário do que muitas vezes acontece, chegou a autoridades nacionais e internacionais, tendo estas condenado o Brasil a indenizar a vítima no valor de 20 mil dólares, responsabilizando o país por negligencia e omissão em relação à violência doméstica. Conforme Dias (2008, p. 14):

Essa é a história de Maria da Penha. A repercussão foi de tal ordem que o Centro pela Justiça e o Direito Internacional - CEJIL e o Comitê Latino Americano e do Caribe para a Defesa dos Direitos da Mulher - CLADEM formalizaram denúncia à Comissão Interamericana de Direitos Humanos da Organização dos Estados Americanos. Apesar de, por quatro vezes, a Comissão ter solicitado informações ao governo brasileiro, nunca recebeu nenhuma resposta. O Brasil foi condenado internacionalmente em 2001. O Relatório da OEA, além de impor o pagamento de indenização no valor de 20 mil dólares em favor de Maria da Penha, responsabilizou 
o Estado brasileiro por negligência e omissão em relação à violência doméstica, recomendando a adoção de várias medidas, entre elas 'simplificar os procedimentos judiciais penais a fim de que possa ser reduzido o tempo processual'.

Foi em face da pressão sofrida por parte da OEA que o Brasil, finalmente, cumpriu as convenções e tratados internacionais do qual é signatário. Daí a referência constante da emenda contida na Lei Maria da Penha à Convenção sobre Eliminação de Todas as Formas de Discriminação contra a Mulher e à Convenção Interamericana para Prevenir, Punir e Erradicar a Violência contra a Mulher.

O sofrimento de Maria da Penha trouxe luz para um assunto complexo e obscuro. Farmacêutica, ela tomou a frente da batalha pela garantia dos direitos das mulheres vítimas de violência doméstica, buscando criar remédios, dessa vez, sociais. Após anos de vergonhas, medos e incertezas, foi sancionada a Lei n. ${ }^{\circ}$ 11.340/2006, datada em 07 de agosto de 2006, a qual ficou conhecida como Lei Maria da Penha. Nos termos estabelecidos, o regulamento busca proteger as vítimas da dor gerada no interior dos lares, dispondo também acerca da criação dos Juizados de Violência Doméstica e Familiar contra a mulher, alterando o Código de Processo Penal, o Código Penal e a Lei de Execução Penal, bem como estabelecendo outras providências. Conforme a contribuição de Campos (2015, online):

\begin{abstract}
A Lei Maria da Penha (LMP) é o principal instrumento legal para a proteção das mulheres em situação de violência doméstica e familiar. Ao instituir uma política pública e um sistema de medidas de assistência e proteção às mulheres em situação de violência por meio de um conjunto articulado de ações da União, dos Estados, do Distrito Federal, dos Municípios e organizações não governamentais, a sua implementação depende de políticas de prevenção e assistência, do comprometimento dos agentes públicos e da articulação de toda a rede (PASINATO, 2015). No entanto, algumas dessas respostas parecem já não dar conta da complexidade do mundo contemporâneo e da vida das mulheres. No entanto, a ausência de serviços em vários cantos do País parece contradizer essa afirmação, pois não pode haver esgotamento de uma política se sequer ela existiu plenamente. Assim, a complexidade da situação requer cautela na análise, pois, se pode haver um afastamento das mulheres de alguns serviços da rede nas capitais, o mesmo não acontece no interior do País, onde sequer há o acesso à rede. Dessa forma, a diversidade das situações de vida das mulheres, a heterogeneidade das perspectivas das redes (SANTOS, 2015) e a diversidade geográfica do Brasil não permitem uma conclusão generalizadora.
\end{abstract}

Neste sentido, a Lei n. ${ }^{\circ}$ 11.340/2006, está sendo meio de transformação social e jurídica. Sabe-se que, além do que já foi implantado, há muito a ser feito quanto a este assunto. As falhas no sistema brasileiro de amparo a dor feminina, ainda vão de encontro ao almejado com esta batalha. É preciso implantar o devido atendimento em lugares que ainda estão desassistidos, assim como dar mais eficácia a esta lei que, sancionada, precisa ser cumprida. No entanto, reconhece-se que o caminho foi iniciado e os resultados, manifestados.

\title{
3.2.1 A violência contra a mulher: uma análise pelo avesso
}


Ao contrário do que se imagina, a luta pela não violência contra a mulher depara-se, em alguns casos, com a falsidade de informações e/ou a intenção perversa de aproveitar-se do gênero que lhe é próprio para alcançar privilégios. Mulheres têm se utilizado desta característica para, fazendo um uso equivocado da Lei n. ${ }^{\circ}$ 11.340/2006, colocar-se na condição de vítima, prejudicando o parceiro que, nesses casos, não cometeu crime algum. Esse comportamento precisa ser observado e jamais aceito.

Ao tratar deste assunto, Tavares da Silva (2016) relata que o uso equivocado desta lei não é algo raro. Advogada atuante, a autora aponta para fatos que poderiam ser considerados um contrassenso, se analisados a partir de um olhar honesto e sensato. Forjar uma realidade para tirar proveito próprio não pode ser tolerado em nenhuma esfera social, quanto mais quando se trata de um assunto tão delicado e doloroso como é o caso da agressão contra o sexo feminino. Isso demonstra que a Lei Maria da Penha, assim como o dano moral, entra para o rol de resoluções legais que, sendo mal utilizadas em petições requeridas por pessoas censuráveis, acabam tornando-se banais e desacreditadas. A profissional afirma que:

Falsas acusações de abusos sexuais e até mesmo de estupro conjugal, inclusive com montagens cênicas, são lastimavelmente realizadas por algumas mulheres que querem se aproveitar indevidamente dos benefícios da Lei Maria da Penha. Por vezes, a mulher até aparece lesionada, mas a agressão não partiu do marido ou companheiro, ou então, a mulher, de tanto agredir o marido, recebe dele a chamada legítima defesa. (TAVARES DA SILVA, 2016)

Esta denúncia não pode ser menosprezada. É de responsabilidade dos operadores do Direito garantir o uso correto do ordenamento jurídico, não permitindo que este seja utilizado de forma deturpada e indigna. É preciso ter o cuidado para não se confundir com os fatos criados sobre uma falsa história ou uma percepção errada de um acontecimento. Isso pode fazer com que os fatos reais não sejam mais respeitados e acolhidos com a devida veemência, levando as verdadeiras vítimas ao desamparo da dúvida. "Mulheres que efetivamente precisam da proteção legal poderão ser vistas como se estivessem falseando a verdade para a autoridade policial ou pelo juiz.” (TAVARES DA SILVA, 2016)

Outro ponto que é passível de discussão a respeito da citada lei está no desamparo às crianças e aos idosos do sexo masculino, tão frágeis quanto os do sexo feminino, assim como a não assistência aos homossexuais, transexuais e transgêneros, os quais, ocupando ou não um lugar feminino dentro das relações, não seriam acolhidos pela citada lei. É importante ressaltar que nem sempre a mulher é o lado mais frágil. Atentar-se para a possível injustiça é uma tarefa que deve ser observada com cuidado por aqueles, não se afastando jamais da 
análise do fato em si, em sua individualidade e particularidade. Conforme Brasil (2005, p. 13 e 14):

Em alguns casos, tanto o homem quanto a mulher podem ser violentos e praticar agressões físicas ou verbais, por terem dificuldade de expressar seus sentimentos de forma respeitosa e civilizada. Esta são as típicas relações de conflito. Pode existir violência física e verbal, mas o que alimenta essa violência não é a desigualdade de poder. O que acontece, nos casos de conflito, é que a relação de amor acaba se transformando numa espécie de ringue de lutas e disputas recíprocas.

Em outros casos, é a mulher quem pratica a violência física ou emocional, infernizando a vida do parceiro ou da parceira do mesmo sexo. Isso também acontece, embora com menos frenquiência.

Assim, pode-se afirmar que a Lei Maria da Penha precisa ser utilizada com cautela e que falhas são evidentes quando reconhece-se que nem sempre a mulher ocupa um lugar de fragilidade e dependência. Os casos devem ser observados concretamente, não podendo ser tolerado que o Direito assuma uma postura fechada e impessoal, mas que a sua atuação seja acolhedora, observando as nuances de cada fato com profundidade e sabedoria. Para fazer justiça, os juristas não podem limitar-se a preconceitos, muito menos permanecer inerte e distante da realidade posta nos autos. O contato se faz necessário para que, de perto, se possa enxergar além dos não ditos.

\section{CONCLUSÃO}

A partir de uma análise panorâmica da violência contra a mulher, a presente pesquisa se encerra com uma sensação de falhas primarias na resolução deste problema. Tendo em vista que são fatos tão antigos e já enraizados na sociedade, entende-se que os avanços sociais foram mínimos diante de tamanha e velha dor. Muitas vezes, as melhorias ficam apenas no mundo das ideias, não sendo efetivadas adequadamente. Mulheres passeiam em momentos de amor e sofrimentos dentro de uma mesma relação, acostumando-se com uma realidade passada de geração para geração.

Apesar de haver uma lei que regulamenta diretamente a problemática aqui discutida, a Lei n. ${ }^{\circ} 11.340 / 2006$, sabe-se que preceitos postos no papel e não efetivados tornam-se letra morta. As autoridades precisam dar seguimento ao trabalho já elaborado nos estudos realizados por diversas áreas do conhecimento, para, assim, fazer valer o esforço e ver esta demanda solucionada. Profissionais da Saúde, da Psicologia, da Sociologia e do Direito deparam-se diariamente com essa questão. No entanto, para que seja solucionada, é necessário que a sociedade como um todo volte-se para este cuidado e que essas mulheres tomem posse 
de si, percebendo-se enquanto sujeitos de direitos, afastando-se desta situação de indignidade e amargura.

Aceitar que o relacionamento deixou de ser aquilo que elas viveram no início e passou a ter uma face violenta, é algo que requer força e uma estabilidade psíquica adequada. A ideia do amor perfeito e para sempre fica turva, enquanto planos são desfeitos e sonhos ruídos. Um período de decepção e incompreensão começa a ser cronometrado. Os dedos que antes caminhavam entrelaçados passam a ser desenhados na pele, como uma marca que jamais sairá da alma. Todo esse processo vai acontecendo ao passo em que a esperança não abandona aquela mulher que, ferida, crê que tudo isso é uma fase, que não passa de um desentendimento e que logo vai ser superada.

Diante deste cenário, o Estado precisa ter um olhar diferenciado para essa questão que ainda não foi solucionada e tende a refletir na família como um todo, bem como no trabalho e nas relações sociais de uma forma geral. Tendo em vista a falta de profissionais suficientes para acolher esta considerável demanda e a total desassistência em alguns lugares do território brasileiro, faz mister apontar para a urgente necessidade de contratar-se novas equipes com profissionais multidisciplinares, capazes de tratar as feridas dessas relações, as quais podem ser consideradas patológicas. É necessário evitar o aumento do número de vítimas, como também cuidar daquelas que já estão inseridas nesta realidade.

Neste sentido, faz-se uma reflexão acerca da forma como a lei está sendo aplicada naquilo que tange a violência contra a mulher. Na certeza do bom amparo legal, entende-se que a falha está no acolhimento às vítimas e na punição aos agressores. O cuidado com aqueles que já estão em um estado de sofrimento, mergulhados em sentimentos de inferioridade, não deveria passar por burocracias tão rígidas, fazendo com que a vontade de promover a justiça se transforme no medo de se expor dentro do grupo ao qual pertence ou, ainda pior, ser mais violentada, caso seja descoberta.

Assim, deve-se ter o cuidado em amparar essa vítima de uma forma mais aproximada, devolvendo a sensação de segurança e dignidade que está perdida. Apreendendo que a dificuldade maior não está nos aspectos legais e sim na forma como estes são efetivados, fazendo da violência doméstica um problema antes de tudo social, percebe-se a presença de uma outra questão que pode dificultar a vitória desta batalha: a econômica. O Brasil é um país que apresenta necessidades em várias áreas, julgadas muitas vezes mais emergentes. Diante da precariedade de verba, muitos serviços são suspensos ou não funcionam como deveriam. 
Portanto, faz mister que maiores recursos sejam destinados a este objetivo, possibilitando que o sistema seja ampliado e que as equipes cheguem a lugares ainda não abraçados.

Por outro lado, acreditando que geralmente a violência contra a mulher faz parte da realidade de alguns grupos e é passada como algo normal de pai para filho dentro de diversos núcleos familiares, entende-se que este é um problema de difícil diagnóstico e de complexa resolução. Resultado de uma cultura patriarcal, a presente questão precisa ser trabalhada em todas as esferas, em especial na infância, fase de construção da subjetividade, a fim de alterar paradigmas. Para isso, se faz necessário compreender a violência como algo antissocial e primitivo, precisando ser urgentemente afastada do atual cenário do século XXI. Uma nova mentalidade deve ser implantada no seio social como elemento promotor e transformador deste filme que ainda se apresenta sem cores. Neste sentido, a escola tem um papel fundamental nesta empreitada. É preciso fazer um trabalho profilático. Políticas públicas podem ser implantadas a fim de levar à sociedade a conscientização pela não violência, fazendo com que a prevenção seja o elemento de mudança social.

\section{REFERÊNCIAS}

BANDEIRA, Lourdes; BATISTA, Analía Soria. Preconceito e discriminação como expressões de violência. Estudos Feministas, Florianópolis, v. 10, n. 1, p. 119, jan. 2002. ISSN 0104-026X. Disponível em: <https://periodicos.ufsc.br/index.php/ref/article/view/S0104-026X2002000100007/8767> Acesso em: 23 junho 2016.

BARROS, Patrícia; SILVA, Fábio Barbirato Nascimento. Origem e manutenção do comportamento agressivo na infância e adolescência. Rev. bras.ter. cogn., Rio de Janeiro, v. 2, n. 1, p. 55-66, jun. 2006. Disponível em <http://pepsic.bvsalud.org/scielo.php?script=sci_arttext\&pid=S1808-56872006000100006> Acesso em: 23 junho 2016.

BEUREN, Ilse Maria. Trajetória da Construção de um Trabalho Monográfico em Contabilidade. In: BEUREN, Ilse Maria. (Org.). Como Elaborar Trabalhos Monográficos em Contabilidade: teoria e prática. 2. ed. São Paulo: Atlas, 2004.

BRASIL. Constituição (1988). Constituição da República Federativa do Brasil. Brasília, DF, Senado, 1988.

Lei n. ${ }^{\circ}$ 11.340. Brasília, DF, Senado, 2006.

Presidência da República. Secretaria Especial de Políticas para as Mulheres.

Enfrentando a Violência contra a Mulher - Brasília: Secretaria Especial de Políticas para as Mulheres, 2005.

BRILHANTE, Aline Veras Morais. Gênero, sexualidade e forró: um estudo histórico social no contexto nordestino. Tese (doutorado) - Universidade de Fortaleza, Universidade Estadual do Ceará, Universidade 
Federal do Ceará. Orientação: Profa. Dra. Ana Maria Fontenelle Catrib. 2015. Disponível em: <https://uol.unifor.br/oul/conteudo/F86027120150417160224954619/Tese.pdf> Acesso em: 23 junho 2016.

BRYAN, Guilherme; VILLARI, Vincent. TELETEMA: volume I 1964 a 1989. A História da música popular através da teledramaturgia brasileira. / Guilherme Bryan e Vincent Villari. São Paulo: Dash, 2014.

CÂMARA, Gabriel Ferreira. A formação do eu e o poder da psicanálise. Cogito, Salvador, v. 11, p. 20-25, out. 2010. Disponível em

<http://pepsic.bvsalud.org/scielo.php?script=sci_arttext\&pid=S1519-94792010000100004> Acesso em: 23 junho 2016.

CAMPOS, Carmen Hein de. Desafios na implementação da Lei Maria da Penha. Rev. direito GV, São Paulo , v. 11, n. 2, p. 391-406, Dec. 2015 . Disponível em: <http://www.scielo.br/scielo.php?script=sci_arttext\&pid=S1808-24322015000200391> Acesso em: 23 junho 2016.

CASIQUE, Leticia; FUREGATO, Antonia Regina Ferreira. Violência contra mulheres: reflexões teóricas. Rev. Latino-Am. Enfermagem, Ribeirão Preto, v. 14, n. 6, p. 950-956, Dec. 2006. Disponível em: <http://www.scielo.br/pdf/rlae/v14n6/pt_v14n6a18.pdf> Acesso em: 23 junho 2016.

CAVALCANTE. Antônio Mourão. Casal: como viver um bom desentendimento. Rio de Janeiro: Rosa dos Tempos, 2001.

CIDADE NEGRA. A Estrada. Quanto Mais Curtido Melhor. 1998 Disponível em: < https://www.youtube.com/watch?v=v7rXgogsqs0>. Acesso em 22 fevereiro de 2016.

D'AVILA NETO, Maria Inacia. O autoritarismo e a mulher: o jogo da dominação machofêmea no Brasil. Rio de Janeiro: Achiamé, 1980

DIAS, Maria Berenice. A Lei Maria da Penha na justiça: a efetividade da Lei 11.340/2006 de combate à violência doméstica e familiar contra a mulher. 2. tir. São Paulo: Editora Revista dos Tribunais, 2008.

FREITAS, Vagner; SILVA, Rosane. CUT: luta por igualdade entre homens e mulheres é desafio para toda sociedade. Rede Brasil Atual. 2014. Disponível em:

$<$ http://www.redebrasilatual.com.br/blogs/blog-na-rede/2014/03/cut-luta-por-igualdade-entrehomens-e-mulheres-e-desafio-para-toda-socieadde-8405.html> Acesso em: 23 junho 2016.

G1. Vídeo mostra 'desculpas' de mulheres que não denunciam violência. São Paulo: G1, 2015.

Disponível em: <http://g1.globo.com/economia/midia-e-marketing/noticia/2015/11/videomostra-desculpas-de-mulheres-que-nao-denunciam-violencia.html $>$ Acesso em: 23 junho 2016.

HERMANN, Leda Maria. Maria da Penha Lei com nome de mulher: considerações à Lei $n^{\circ}$ 11.340/2006: contra a violência doméstica e familiar, incluindo comentários artigo por artigo. Campinas, SP: Servanda Editora, 2008. 
LAMANNO-ADAMO, Vera Lúcia C.. Violência doméstica: uma contribuição da psicanálise. Ciênc. saúde coletiva, Rio de Janeiro , v. 4, n. 1, p. 153-159, 1999. Disponível em: <http://www.scielo.br/scielo.php?script=sci_arttext\&pid=S1413-81231999000100013> Acesso em: 23 junho 2016.

LIMA, Elizabeth Maria Freire de Araújo; YASUI, Silvio. Territórios e sentidos: espaço, cultura, subjetividade e cuidado na atenção psicossocial. SAÚDE DEBATE | RIO DE JANEIRO, V. 38, N. 102, P. 593-606, JUL-SET 2014. Disponível em:

<http://www.scielo.br/pdf/sdeb/v38n102/0103-1104-sdeb-38-102-0593.pdf> Acesso em: 23 junho 2016.

MADEIRA, Lígia Mori; ENGELMANN, Fabiano. Estudos sociojurídicos: apontamentos sobre teorias e temáticas de pesquisa em sociologia jurídica no Brasil. Sociologias, Porto Alegre, ano 15, no 32, jan./abr. 2013, p. 182-209. Disponível em:

<http://www.scielo.br/pdf/soc/v15n32/08.pdf > Acesso em: 23 junho 2016.

MOTTA, Joaquim Zailton Bueno. AMOR E RIVALIDADE SEXUAL. Petrópolis: Editora Vozes, 1989.

QUEIROZ, Rafael Mafei Rabelo. MONOGRAFIA JURÍDICA: Passo a Passo - Projeto, pesquisa, redação e formatação. São Paulo: MÉTODO, 2015. Disponível em:

$<$ https://integrada.minhabiblioteca.com.br/\#/books/978-85-309-6298-

2/cfi/6/30!/4/142/4/2@0:0>. Acesso em: 20 mar. 2018. online.

REALE, Miguel. Lições Preliminares de Direito. 27. ed. São Paulo: Saraiva, 2004.

RICHARDSON, Roberto Jarry. Pesquisa social: métodos e técnicas. 3. ed. São Paulo: Atlas, 1999.

SANTOS, Vinícius Oliveira dos; GHAZZI, Mercês Sant'Anna. A transmissão psíquica geracional. Psicol. cienc. prof., Brasília, v. 32, n. 3, p. 632-647, 2012 . Disponível em: <http://www.scielo.br/scielo.php?script=sci_arttext\&pid=S1414-98932012000300009> Acesso em: 23 junho 2016.

SOUZA, Tharso Peixoto Santos e. O lugar do desejo feminino frente à violência. Reverso, Belo Horizonte, v. 33, n. 62, p. 85-91, set. 2011 . Disponível em: $<$ http://pepsic.bvsalud.org/scielo.php?script=sci_arttext\&pid=S010273952011000200010\&lng=pt\&nrm=iso> Acesso em: 13 julho 2016.

TAVARES DA SILVA, Regina Beatriz. Violência doméstica: risco de banalização da lei. Jornal ESTADÃO. [online] Blog Fausto Macedo (repórter). 2016. Disponível em: $<$ http://politica.estadao.com.br/blogs/fausto-macedo/violencia-domestica-risco-debanalizacao-da-lei/> Acesso em: 13 julho 2016. 